\title{
Exploring the impact of information and communication technology on employees' work and personal lives
}

\begin{tabular}{|c|c|}
\hline \multicolumn{2}{|c|}{$\begin{array}{l}\text { Authors: } \\
\text { Wihan de Wet }{ }^{1} \\
\text { Eileen Koekemoer } \\
\text { Jan Alewyn Nel }\end{array}$} \\
\hline \multicolumn{2}{|c|}{$\begin{array}{l}\text { Affiliations: } \\
{ }^{1} \text { WorkWell Research Unit, } \\
\text { North-West University, South } \\
\text { Africa }\end{array}$} \\
\hline \multicolumn{2}{|c|}{$\begin{array}{l}{ }^{2} \text { Department of Human } \\
\text { Resource Management, } \\
\text { University of Pretoria, South } \\
\text { Africa }\end{array}$} \\
\hline \multicolumn{2}{|c|}{$\begin{array}{l}\text { Corresponding author: } \\
\text { Jan Alewyn Nel, } \\
\text { alewyn.nel@up.ac.za }\end{array}$} \\
\hline \multicolumn{2}{|c|}{$\begin{array}{l}\text { Dates: } \\
\text { Received: } 24 \text { Nov. } 2015 \\
\text { Accepted: } 17 \text { Feb. } 2016 \\
\text { Published: } 14 \text { June } 2016\end{array}$} \\
\hline \multicolumn{2}{|c|}{$\begin{array}{l}\text { How to cite this article: } \\
\text { De Wet, W., Koekemoer, E., \& } \\
\text { Nel, J.A. (2016). Exploring the } \\
\text { impact of information and } \\
\text { communication technology } \\
\text { on employees' work and } \\
\text { personal lives. SA Journal of } \\
\text { Industrial Psychology/SA } \\
\text { Tydskrif vir Bedryfsielkunde, } \\
42(1) \text {, a1330. http://dx.doi. } \\
\text { org/10.4102/sajip.v42i1.1330 }\end{array}$} \\
\hline \multicolumn{2}{|c|}{$\begin{array}{l}\text { Copyright: } \\
\text { (C) 2016. The Authors } \\
\text { Licensee: AOSIS. This } \\
\text { is licensed under the } \\
\text { Creative Commons } \\
\text { Attribution License. }\end{array}$} \\
\hline \multicolumn{2}{|l|}{ Read online: } \\
\hline 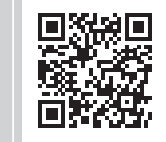 & $\begin{array}{l}\text { Scan this QR } \\
\text { code with your } \\
\text { smart phone or } \\
\text { mobile device } \\
\text { to read online. }\end{array}$ \\
\hline
\end{tabular}

Orientation: Technology has become part of society's everyday functioning, changing rapidly and providing widespread mobility. Employees are moving towards a continually connected lifestyle, a situation in which information and communication technology (ICT) seem to have become omnipresent.

Research purpose: The overall objective of this research was to investigate the influence of ICT on employees' work and personal lives.

Motivation for the study: The impact of ICT on the work and personal lives of employees has never been researched before, which motivated the current study.

Research approach, design and method: A qualitative research design, with a sample of 25 employees, was followed. Semi-structured interviews were conducted to collect data, and the interviews were recorded, transcribed, and processed through thematic analyses.

Main findings: Five themes with sub-themes were extracted: The positive and negative experiences of ICT both within the work and personal lives of employees, the increased expectations brought about by ICT usage, and the role of ICT on relationships. Findings highlighted that although ICT are generally perceived as positive, employees should make a conscious decision in managing their ICT to decrease the negative impact thereof on their work and personal lives.

Practical/managerial implications: Overall, the general positive experiences of ICT outweigh the negative experiences, and findings almost suggest that as the quantity of communication increased, the quality of conversations decreased.

Contribution/Value add: This study provides a holistic understanding of the impact of ICT on the work and personal lives of employees.

\section{Introduction}

The world changed drastically in the past few decades with a large majority of these changes due to the increased infiltration of technology in society. This alters the way individuals think, interact, and complete their tasks (Marius, 2012). Schmidt, Pfleging, Alt, Sahami and Fitzpatric (2012) mentioned that abundant access to ICT did not only improve the world but also transformed society drastically. According to Rincon, Vecchi and Venturini (2012), these advances in ICT brought about a technological revolution, which modified not only the manner in which individuals conduct business but also the way in which people complete daily household activities. Currently, a 24/7 working culture exist, largely due to the connectedness provided by ICT (Piazza, 2007). Everyday items are becoming 'smart' (i.e. smartphones, smart cars, and smart homes) with the ability to connect and provide information at the touch of a button, mostly to increase the quality of lives for its users. In an attempt to stay abreast with these changes, governments are investing billions to convert cities into smart hubs, connecting people to city-wide WiFi networks. These networks provide up-to-date information on government programs, traffic, as well as local attractions and restaurants. Organisations are also adopting this trend by investing large capital in ICT in order to remain competitive, and also increase efficiency and cost-effectiveness (Tusubira \& Mulira, 2004).

Currently, technology is advancing rapidly. In 2014, the International Telecommunications Union (ITU) (Delmas, 2014) reported a mobile cellular subscription rate of 6.95 billion. The number grew from 2.2 bn in 2005, thus, illustrating a growth rate of $212 \%$ in 9 years. This also indicates that 
almost $96 \%$ of the global population currently owns or operates a mobile phone. The ITU further reported a fixed broadband growth rate of 105\% between 2007 and 2014 with an astonishing growth rate of $763 \%$ for mobile broadband devices during the same time period. Not only is there a growing usage of ICT devices but the amount of devices available increased as well. Two other groups of devices providing access to the internet for communication and information purposes (i.e. tablets and gaming consoles), also show a rise in sales.

More recent research in the field of ICT seems to focus more on the influence or impact certain ICT devices - or the particular usage of such a device - have on a specific environment or concept. The main focus is usually centred within the education environment (how technology can be used to improve teaching) and on the impact of ICT diffusion in general (Achimugu et al., 2010; Kumar \& Prasad, 2014; Leask \& Pachler, 2013; Lindquist, 2013; Shirazi et al., 2010; Tolani-Brown, 2010; Van der Knaap, 2014). Other research also focuses on aspects such as productivity (Kıliçaslan et al., 2013), innovation (Arvanitis \& Loukis, 2014; Higon, 2011), and performance of organisations (Arvanitis \& Loukis, 2014; Higon, 2011; Kılıçaslan et al., 2013; Preda et al., 2014; Saltari et al., 2013).

Within the work environment, it seems most research is focused on the influence of ICT on certain industries or organisations (Hall et al., 2013; Higon, 2011; Livingstone, 2012; Ollo-Lopez \& Aramendia-Muneta, 2012). It is evident that current research often ignores the possible influence these devices could have on the individuals or employees concerned. Studies that do indeed investigate ICT's impact on individuals or employees follow a quantitative research approach (Berkowsky, 2013; Fallahi, 2011; Koutamanis et al., 2013; Salehan \& Negahban, 2013; Zorn, Hector \& Gibson, 2008), with only a few studies employing mixed-method approaches in their research (Lasrado \& Bagchi, 2011; Lindsay et al., 2007) and none utilising inductive, explorative approaches.

\section{Research purpose and objectives}

Based on the introduction, this study aims to explore the influence of ICT on employees' functioning in various work environments (as opposed to certain industries or organisations). This will provide a holistic understanding of the impact of ICT on the work lives of employees and how it in turn affects the personal lives of employees. Therefore, the specific objectives of this research are (1) to explore the role of ICT on employees' work life, (2) to explore the role of ICT on employees' working relationships, (3) to explore the role of ICT on employees' personal life, and 4) to explore the role of ICT on employees' personal relationships. In the next section, a literature review will aim to state the perspective of the study, conceptualise ICT in order to provide a general idea of what the concept entails and to explore the impact of ICT on the work lives and personal lives of employees.

\section{Literature review}

\section{Constructivism paradigm as perspective in the study of information and communication technology}

Defining information and communication technology: Although various definitions of ICT exist, Stahl et al. (2010) mention that applying the broad term of ICT allows one to focus on a range of views and technologies. Stahl et al. (2010) goes on by emphasising that to define ICT it is better to avoid other forms of technologies such as biotechnology, nanotechnology and cognitive technologies (also known as NBIC technologies). For the purpose of this research, the definition provided by Afolabi and Abidoye (2011:14) seems to fit the desired context as they define ICT as 'the usage of electronic devices such as computers, telephones, internet and satellite systems to store, retrieve and disseminate information in the form of data, text image and others'. This definition allows researchers to focus on ITC as a whole (i.e. all applications). Such a focus implies more than merely the influence of mobile phones, computers, and certain ICT applications (such as social networking platforms or instant messaging applications), as is the case with most current research endeavours. The Collins Dictionary defines a smart device as electronic devices that are connected to other devices or networks through different protocols such as Bluetooth, NFC, Wi-Fi, and $3 \mathrm{G}$ that can operate to some extent interactively and autonomously.

ICT in organisations: Tusubira and Mulira (2004) found that it became necessary for organisations to integrate ICT into organisational functions in order to increase efficiency, cost-effectiveness, and competitiveness. This finding is supported by multiple researchers who also found that ICT increased organisational productivity in some way or the other (Kamaruzzaman et al., 2010; Kimathi, 2012; Mortagy et al., 2005). According to Lasrado and Bagchi (2011), hardly any business transaction currently occurs without it being captured digitally at some point. Even though ICT was present in the workplace almost two decades ago, presently it is viewed as a basic necessity and its absence in the workplace causes major dissatisfaction. Zorn et al. (2008:1) add that 'work becomes more intense, workers are displaced, surveillance increases, workers' bargaining power is reduced and their skills (in many cases) become obsolete, devalued, or constrained by ICT-imposed structures'.

Influence of ICT on the work and personal lives of employees: When considering the influence of ICT on the personal lives of employees, Papadakis and Collins (2001) mention that research is 'extremely limited in scale and

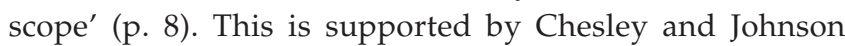
(2010) who contend that this realm is still understudied. The little research that exists only covers aspects such as time displacement, teleworking of parents, psychological well-being, informatics and healthcare, and the influence of video games on children (Papadakis et al., 2001). Evidently 
there is a need for research on the influence various forms of ICT device usage can exert on individuals' work and personal domains.

Madden and Jones (2008) indicate that ICT influences individuals positively and negatively. Some of these positive effects include employees' improved ability to do their job and to share ideas with co-workers, as well as more flexible working hours. The negative effects include increasing work demands and hours, higher stress levels, and the difficulty to disconnect from work when at home. Mobile phones also provide employers the opportunity to be connected to their employees at all times (Carroll et al., 2002), which erases the separation line between work and personal time. These results show that ICT may influence an individual's work domain and personal domain, as well as the relationships within these domains.

From the information mentioned above, it is evident that various ICT devices and platforms have influenced society. However, people's understanding of ICT and its influence in a broader sense is not well-documented. Schmidt et al. (2012) points out: How individuals deal with ICT in the 21st century remains a challenging issue, especially nowadays when employees no longer focus on a single ICT device, but have to contend with multiple ICT devices (e.g. mobile phones, tablet computers, netbooks, smartphones, laptops, and desktop computers). Moreover, the researchers who do investigate the influence of ICT on individuals or employees only focus on certain ICT devices or applications. Thus, to investigate the influence of ICT in its broader sense, on employees and their environments, the present research followed a qualitative approach.

\section{Research design \\ Research approach}

The role of ICT, as mentioned previously, has not been studied adequately, and this prompted the researcher to investigate the phenomena in depth, which supports the notion of a qualitative research design (Snape \& Spencer, 2003). Within this framework, a phenomenological approach was utilised because the researchers were interested in discovering the subjective reality of employees in their experience of ICT and how it impacted their work and personal lives (Snape \& Spencer, 2003).

\section{Research strategy}

This study followed a multiple case study strategy because employees working for various selected organisations were included. However, some inclusion criteria were followed in identifying and approaching the units of analysis (employees). Therefore, the following inclusion criteria were applied: participants were required to (1) own and use more than two always connected ICT devices for both work and personal purposes, (2) be willing to be interviewed, and (3) be employed in an organisation where ICT is part of their everyday working life.

\section{Research method}

\section{Research setting}

Interviews were conducted in a professional manner and at the convenience of the participants. The researcher made sure that the interviews were conducted in an environment where the participants felt comfortable and minimal or no disruptions could be expected. To help provide a comfortable setting, the interviews were conducted in the participant's home language and the majority of the interviews took place at the participant's home or a private boardroom at his or her office.

\section{Entrée and establishing researcher roles}

The first author initiated the research and fulfilled a more active role in the overall research project. The roles he played were that of conceptualiser of the study, data collector, data evaluator, and documenter of research. The second author assisted with conceptualising the research study, acted as co-coder for the data, and co-documenter of the research. The third author acted as quality controller of the final documented research. As no single employer or organisation was approached for the research, no mediator or gatekeeper was required. Permission and informed consent was thus originally obtained from each participant.

\section{Research participants and sampling methods}

A combined, purposive, and snowball non-probability sample $(N=25)$ was utilised. According to Maree (2008), snowball sampling is a method in which the researcher uses social networks of participants who are already contacted, in order to reach other participants who could partake in the study. As the goal of qualitative-data research is to enrich the understanding of an experience, it requires the purposive selection of participants (Polkinghorne, 2005). Therefore the researcher had to select people from whom he could learn substantially about that experience which adheres to the research strategy guidelines for this study (Polkinghorne, 2005).

Participants were mainly males (64\%), aged between 24 years and 60 years, with $36 \%$ aged between 24 years and 30 years. The majority of the participants (72\%) were married with $63 \%$ of the married participants indicating that they have children. Participants were employed in the following industries: finance sector $(20 \%)$, education and the legal industry $(16 \%)$, medical $(8 \%)$, mining $(8 \%)$, and other business services such as real estate and manufacturing (32\%). The majority of the participants $(60 \%)$ indicated that they use three ICT devices and $32 \%$ of participants use four or more ICT devices on a daily basis.

\section{Data collection methods}

Data were collected through semi-structured interviews, which allowed the researcher to focus on specific themes whilst staying true to the conversational style of interviewing (Raworth et al., 2012). Interview questions were finalised after three pilot interviews, which allowed the researcher to 
gather valuable information on the expected data from each question, as well as the opportunity to refine the questions (Hill et al., 2005). Four standard questions were posed in every interview, followed by probing and follow-up questions:

- For what purposes or reasons and how do you use your ICT devices at work?

- For what purposes and reasons and how do you use your ICT devices in your personal environment?

- How do you experience the role of your ICT devices in your work and work relationships?

- How do you experience the role of your ICT devices in your personal relationships?

Prior to the interviews, the researcher contacted the participants to schedule an appointment at their convenience. The participants were informed beforehand that the content of the interview will be kept confidential and will only be used for purposes of research. Moreover, before the interview commenced, the participants were made aware of the research objective and was provided a brief background on the research to help them grasp the context. The participants were also informed of the process which the interview will follow and were given the opportunity to ask questions, if any. All participants were required to sign an informed consent form together with completing a biographical questionnaire. Finally, the participants were informed that they had the right to withdraw from the interview or the research at any time. They were provided with the researcher's contact details in case of any further queries or contributions.

\section{Data recording}

With the consent of the participants, the interviews were tape-recorded and stored on a secured server to which only the researcher had access. To ensure confidentiality, the recordings, notes, and completed forms were stored in a safe place. A list of the participants was created in which each participant was allocated a number. Throughout the research, the corresponding number of a particular participant was used to store the relevant forms, recordings, and data. Field notes (completed after each interview) were used to capture the thoughts of the researcher during the interviews for further analysis at a later stage (Bogdan \& Biklen, 1998; De Vos et al., 2011).

\section{Strategies employed to ensure data quality and integrity}

Mays (2000) mention that although there is no easy solution to limit the likelihood of errors in qualitative research, there are methods to improve the validity of the data and mentions various approaches. In line with the approach of respondent validity (Barbour, 2001), the researcher contacted a random sample of participants to verify the findings. It was found that the analyses were in line with that of the participants' experiences. For the purpose of clear exposition of methods used, the research furthermore clearly outlines the process and procedures followed as part of data collection and analysis. Focusing on reflexivity and relativism (Mays, 2000), the researcher avoided any bias, particularly from his own perception of the phenomenon. Throughout the data analysis, the researcher discussed and explored with the cocoder possible contradicting elements to the explanation of ICT. In addition, the researcher provided credibility by adopting appropriate research methods and using random sampling and debriefing sessions with his superiors (Shenton, 2004). Furthermore, to ensure transferability and dependability (Shenton, 2004), detailed descriptions and in-depth methodological descriptions of the phenomenon in question were provided. To ensure conformability, the researcher was aware of his own beliefs and assumptions and recognised the shortcomings within the current study (Shenton, 2004).

\section{Data analysis}

The verbatim transcribed interviews along with the field notes were analysed through thematic analysis. Thematic analysis is the process of identifying, analysing, and reporting patterns from responses or data which allow the researcher to organise and describe the data in detail (Braun \& Clarke, 2006). The six phases of thematic analysis of Braun and Clarke (2006) are discussed. They include familiarising yourself with the data, generating initial codes, searching for themes, reviewing themes, defining and naming themes, and producing the report.

Phase 1: Familiarising yourself with the data: The researchers began the analysis by firstly reading through the transcribed interviews whilst listening to the recordings to ensure that they were fully familiar with the data (Maree, 2008).

Phase 2: Generating initial codes: The first author developed initial codes, while the second author acted as co-coder during this process. The involvement of a co-coder during data analysis enhances the consistency of the results and helps to establish the validity and consistency of the data (Du Plessis \& Human, 2007).

Phase 3: Searching for themes: After codes were identified, the first author and co-coder began to categorise corresponding topics into themes. For this study, five themes emerged.

Phase 4: Reviewing themes: The first author and co-coder used the notes and categorised items from the first interview to guide the process whilst coding the second interview. This process continued throughout the coding of all 25 interviews and is known as the constant comparative method (Wagner et al., 2012)

Phase 5: Defining and naming themes: The first author and co-coder then extracted all the notes, including the original text for the notes, and stored each topic in a separate file to use for analysis. This allowed the researcher a holistic view of a specific topic from all 25 interviews.

Phase 6: Producing the report: The topics were refined further by the authors whilst working through the combined 
notes on a specific topic. The authors investigated each topic that was extracted along with its original text, after which the topics were categorised into themes. Based on the rich data received from the interviews, four main themes were extracted which were further subdivided into smaller sub-themes.

\section{Reporting style}

The four main themes were reported through illustrative material such as figures and tables. The use of illustrative material such as figures was employed to ensure that the reader kept track of the flow of data as the researcher intended (Wagner et al., 2012). The data analysis yielded rich and informative information on the use and role of ICT on employee's work and family domains, including the relationships within these domains.

\section{Results}

The main purpose of this research was to explore the role of ICT on employees' work and personal domains. Five themes were extracted, namely (1) positive experiences of ICT, (2) negative experiences of ICT, (3) the dependency on ICT usage, (4) new and additional expectations brought about by ICT usage, and (5) the role of ICT usage on relationships (Table 1).

\section{Theme 1: Positive experiences of information and communication technology}

It was evident from the analysis that most participants experience the increase in their productivity and efficiency as positive. This does not only apply to their work but also outside their work context. Participants would often mention that their ICT devices allow them to work faster and to multitask, but still maintain a high quality standard of work:

'I think our quality is higher and I think when you look at things like productivity, yes there are more outputs. As far as quality is concerned I do not have any doubts that it had a tremendous impact.' (Participant 6)

Participants further mentioned that their use of ICT increased their availability to both their organisation and clients, and provided them with easy access to work documents and the system. As stated by the participants, ICT devices allow one to work from home offices and provide immediate advice and cost estimations to clients from the comfort of one's home or office. This is mentioned in this response:

'Every device that I have, my cell phone, my laptop, my tablet, they are all connected with my work emails. I am never away from my work basically.' (Participant 7)

Participants also indicated that ICT allowed them to save time by eliminating travel to meet clients as they could provide their services through ICT systems such as e-mail and Skype. Much in the same way that ICT allowed participants to work from their client's offices and homes, these devices also support globalisation by allowing employees to work across geographical boundaries. One participant, a medical sales representative for the Africa and Middle East, mentioned that without his ICT he would not be able to cater to so many countries as his job required:

'I wouldn't be able to do as many countries as I do. I wouldn't be able to move as fast as I do. I certainly couldn't do the job that I do, in the time allocated.' (Participant 9)

Other participants added that ICT allowed them to establish and maintain virtual offices, especially between towns, which enabled managers to stay constantly in contact with employees at both offices, as well as with clients from various towns.

Participants further indicated that, outside of the work context, ICT allowed them to easily reach and stay in touch with family members. Most of the participants also indicated that their ICT allows them to stay in contact with family members

TABLE 1: Theme 1: Positive experiences of ICT.

\begin{tabular}{|c|c|c|}
\hline Participants experience & Sub-theme & Associated meaning \\
\hline \multirow[t]{7}{*}{$\begin{array}{l}\text { ICT as positive at work } \\
\text { because it }\end{array}$} & Allows them to be more effective and productive & $\begin{array}{l}\text { It allows a person to work faster, communicate easier and more rapidly, makes work easier, } \\
\text { and improves the quality of work }\end{array}$ \\
\hline & Increases their availability & Allows a person to be available continuously to a client or employer \\
\hline & Provides easy access & $\begin{array}{l}\text { Allows a person to have continuous access to work information, systems, and documents } \\
\text { even when not at work, which creates a mobile workforce }\end{array}$ \\
\hline & Saves time & Saves time by removing traveling time as ICT can be used instead to perform tasks quicker \\
\hline & Increases the competitive advantage of organisations & $\begin{array}{l}\text { Gives organisations a competitive advantage by providing more options to communicate to } \\
\text { and with customers and clients }\end{array}$ \\
\hline & Facilitates obtaining and sharing of information & $\begin{array}{l}\text { Allows a person to stay informed on work-related topics and information, and enables to } \\
\text { share and obtain information quickly and easily }\end{array}$ \\
\hline & Supports globalisation & $\begin{array}{l}\text { Allows people to interact and work across time zones and countries, making the world 'a } \\
\text { smaller place' }\end{array}$ \\
\hline \multirow[t]{5}{*}{$\begin{array}{l}\text { ICT as positive outside the } \\
\text { work context because it }\end{array}$} & Allows users to reach family members & $\begin{array}{l}\text { Makes it possible to always get hold of family and friends (specifically in emergencies) and } \\
\text { to keep in touch with friends and family who are close-by or distant }\end{array}$ \\
\hline & $\begin{array}{l}\text { Provides access and synchronisation to and of } \\
\text { information }\end{array}$ & $\begin{array}{l}\text { Provides 'always connected' access to all your files and documents through synchronisation } \\
\text { software such as Dropbox }\end{array}$ \\
\hline & Increases personal efficiency & $\begin{array}{l}\text { Makes it possible to be more flexible with your time, allows you to multi-task, and makes a } \\
\text { person more effective }\end{array}$ \\
\hline & Facilitates obtaining and sharing of information & Makes it possible to easily and quickly share and obtain information \\
\hline & Provides cheaper alternative & Using ICT is less expensive than the alternative with regards to communication \\
\hline
\end{tabular}

ICT, information and communication technology. 
living abroad. This form of contact allows them to still be part of each other's lives through applications such as Skype and Whatsapp, which in some instances are much cheaper than the alternative.

Interestingly, although the positive experiences almost outweighed the negative ones, participants do sometimes experience the use of ICT as negative. Subsequently Theme 2, the negative experience of ICT both at work and outside the work context are discussed and summarised in Table 2.

\section{Theme 2: Negative experiences of information and communication technology}

In this sample, participants experienced increased pressure due to ICT usage as negative within their work domain. Various participants explained this as follows: ICT allows them to be more efficient, productive, and available, as mentioned in Theme 1; therefore, it also increases their work demands. The reason is clear: they are enabled to perform more work tasks in less time, thus being more productive.

Participants mentioned further that employees would often use their ICT at work as a convenient excuse, in order to avoid confrontational conversations. It is seen as much easier to write a negative or blaming e-mail to someone, than actually speaking to him/her in person or 'eye-to-eye'. On the contrary, one participant did, however, explain that when dealing with confrontational situations over e-mail, using ICT allowed him to reconsider what he wanted to say before he sent the mail. The following illustrates the negative aspect of ICT:

'I think particularly when you work with people, it is easier for them to use their computer and write a 'snotty' e-mail rather than looking you in the eye.' (Participant 24)

From the analyses it also seemed that ICT compromised the chain of command or hierarchy at work. Various participants explained that ICT made it easy to communicate with any of their co-workers when requesting assistance with a task, even though that person did not report to them directly. According to participants, from the perspective of a manager, such easier general communication makes it difficult to prioritise certain tasks for their subordinates, seeing that they constantly receive tasks from other managers or co-workers. This makes it difficult for managers to manage their subordinates' time and priorities, as can be deduced from the following response:
'So let's say, the manager has a certain planning on what a person should do but in the meantime he is getting so much tasks or requests from everyone else that he can't do it...' (Participant 14)

Furthermore, participants stated that ICT usage creates a distraction. Although most participants indicated this as a negative experience outside the work context, some did mention that ICT also creates distraction at work. One participant specifically highlighted the distraction of his device linked to his work emails. When using the device in his personal environment for personal reasons, the notification of a work e-mail distracts him and he ends up checking the e-mail that came through on his device. This caused him to lose track of time and the ITC interfered with his work-life interaction. One participant also mentioned interference by their ICT, not necessarily because it distracts them but in general they would often find themselves spending more time as intended on their devices:

'It is bad because you just want to answer quickly and then after five times of 'answering quickly' it takes an hour of your evening and it is difficult to manage because you want to be diligent in doing so.' (Participant 8)

Participants also pointed out that the use of ICT devices to communicate led to decreased face-to-face communication, seeing that it is currently much easier and more convenient to communicate with someone using instant messaging applications such as SameTime and Skype, even if the discussants are in the same office building. Interestingly, one participant mentioned that he purposively avoids using instant messaging applications to communicate with people within his proximity. He rather actively tries to have face-to-face conversations with people, seeing that he experienced the loss of such direct communication as negative. Very much related to the above mentioned negative experiences regarding the use of ICT, participants also mentioned the dependability which comes with ICT usage as summarised in Table 3.

\section{Theme 3: Dependency on information and communication technology usage}

From the analyses, it was evident that the role of ICT was also evident in terms of dependability and the negative effect thereof.

One of the most interesting findings was that ICT changed the norm of availability. In the past, people were not expected

TABLE 2: Theme 2: Negative experiences of ICT.

\begin{tabular}{|c|c|c|}
\hline Participants experience & Sub-theme & Associated meaning \\
\hline \multirow[t]{3}{*}{$\begin{array}{l}\text { ICT usage at work as negative } \\
\text { because it }\end{array}$} & Increases pressure & $\begin{array}{l}\text { The usage of ICT in the workplace creates additional pressures regarding communication and } \\
\text { effectiveness }\end{array}$ \\
\hline & Can be used as an excuse & People use ICT as a convenient excuse to avoid direct communication \\
\hline & Compromises the chain of command & $\begin{array}{l}\text { The usage of ICT at work removes the hierarchy of command regarding communication in } \\
\text { the workplace }\end{array}$ \\
\hline \multirow[t]{4}{*}{$\begin{array}{l}\text { ICT usage as negative outside the } \\
\text { work context because it }\end{array}$} & Creates a distraction & $\begin{array}{l}\text { The use of ICT devices can create or become a distraction from work or from the personal } \\
\text { domain }\end{array}$ \\
\hline & Makes people lose track of time & The use of ICT lets a person in some cases lose track of time whilst using the device \\
\hline & Compromises employees' confidentiality & $\begin{array}{l}\text { The use of ICT creates an electronic, non-erasable paper trail and allows unwanted people to } \\
\text { obtain access to personal or confidential information }\end{array}$ \\
\hline & Decreases face-to-face communication & The use of ICT to communicate decreases face-to-face communication between people \\
\hline
\end{tabular}

ICT, information and communication technology. 
to be reachable continually by both their family and their employer. However, the current expectation is that an individual should be reachable through his/her ICT devices. The following response illustrates this situation well with the participant expressing her concern when she has difficulty reaching her husband on his mobile phone:

'If you can't get hold of him you begin to panic, as a simple example, if I try to get hold of Kobus and his phone is off I start to panic because I think, why is he not there, then it ends up to be something simple like he is in a meeting and he had to turn his phone off.' (Participant 18)

The usage of ICT also brought the aspects of addiction and dependability to the front, where employees become so dependent and addicted to their ICT that it may become almost problematic with negative effects, as illustrated below:

'I think that we are at that point these days where you hardly go without your cell phone, not only for work. I think to a big degree it is more for social networks, people on Facebook and Twitter and BBM and those type of things, so it is very traumatic for a person to be without his phone.' (Participant 14)

In addition to experiencing the usage of ICT as both positive and/or negative, data analyses revealed the increase in expectations brought about by the usage of ICT (Theme 3). This theme is summarised in Table 4 .

\section{Theme 4: New and additional expectations brought about by information and communication technology usage}

Table 4 expounds the increased expectations caused by using ICT devices. Participants deemed it a positive side of ICT that it provides access and creates availability for interaction. Nevertheless, a number of participants mentioned that this also created an expectation, as mentioned previously, that they must respond to communications immediately:

'Today it is immediate, if your clients send you an e-mail it is there, no matter where in the world you may be. He wants an answer because he knows you have received it. It has increased the pace of life enormously - the working life.' (Participant 1)

The participants also alluded to the fact that advancements in technology also brought about an expectation of higher productivity. One participant specifically mentioned her frustration with others' perception that she should be able to do certain tasks 'with the push of a button', which according to her is not reality. Finally, the participants pointed out that ICT created the expectation that people should always be available to their family, friends, and employer. It was mentioned previously that ICT created the expectations of reaching family and friends more easily. However, some participants experienced the opposite: In the same way they expect family and friends to be reachable, they are also expected to be more reachable and available themselves to their family, friends, and their employer. One participant mentioned a specific occurrence where a co-worker expected her to be available for work over a weekend, which created conflict within their relationship as well as with her family. This relates very well to the last theme extracted which was how ICT also influences employees' relationships. Table 5 elaborates on Theme 4 further.

\section{Theme 5: The role of information and communication technology usage on relationships}

As derived from Table 5, much the same as with ICT's influence, the role of ICT on relationships can be experienced as both positive and negative. Most participants indicated that they experience the role of ICT on their relationships as positive, due to the following gains: it allows them to establish and maintain relationships, enables communication, creates more productive relationships, and increases their frequency of communication. On the negative side, the analysis indicated that ICT usage decreases the need for interaction, takes away time from relationships, and inhibits the intimacy of conversations.

The most mentioned role of ICT on relationships is the ability to maintain personal relationships, especially across geographical boundaries:

'I have a very good friend in England, who's a colleague of mine. I most probably speak to him every second day on Skype and if I didn't have that technology I certainly wouldn't have the same kind of relationship or get the information that I need from him.' (Participant 9)

Regarding the decreased need for interaction created by ICT usage, participants pointed out that social media reduced the need to interact with family and friends as they are able to get an update on someone's whereabouts through social-media sites such as Facebook and Twitter. One participant specifically

TABLE 3: Theme 3: The dependency on ICT usage.

\begin{tabular}{ll}
\hline Sub-theme & Associated meaning \\
\hline Total dependence on ICT for work & People become dependent on their ICT devices to be able to work \\
$\begin{array}{l}\text { Addiction to ICT } \\
\text { Changes the norm for availability }\end{array}$ & People become addicted to their devices; they are afraid to go anywhere without their devices \\
Creates a general dependency & With ICT becoming ever-present, the norm changes for a person to be accessible throughout (to work or family) \\
\hline
\end{tabular}

ICT, information and communication technology.

TABLE 4: Theme 4: New and additional expectations brought about by ICT usage.

\section{Sub-themes}

Increases the expected time of response

Creates the expectation for higher productivity

Increases the expectation of continuous availability

$\mathrm{ICT}$, information and communication technology.

\section{Associated meaning}

Creates the expectation that people will be available and will be able to respond immediately to a request

Creates the expectation that people will be more productive as ICT allows a person to be more efficient Creates the expectation that a person will be available throughout to work as the ICT provides this opportunity 
TABLE 5: Theme 5: The role of ICT usage on relationships.

Sub-themes
Maintains personal relationships
Inhibits personal conversations and intimacy
of conversations
Usurps time in relationships
Enables communication between co-workers
Decreases the need for interaction
Builds productive relationships
Establishes new relationships
Enhances communication

Associated meaning

Helps maintain relationships with family and friends both close-by and distant

Decreases the personal and intimate aspect in conversations and relationships by removing face-to-face communication and using ICT to communicate in simple terms

Creates distractions and takes time away from one's family either through working or spending time on devices instead of with family and friends. In some cases, this distraction can occur in the middle of a face-to-face conversation

Allows a person to communicate easily and quickly with co-workers

By using ICT for communication and on social networks, it decreases the need to communicate

Allows for more productive relationships by saving time and making communication easy and quick

Enables a person to establish new relationships, even across geographical boundaries

Increases the frequency of individuals' communication with family, friends, and co-workers

ICT, information and communication technology.

mentioned that, when he attended his high school reunion, he found he had no topics to discuss with old friends. He was already aware of developments in their lives through the mentioned social-media sites.

An interesting sub-theme identified was the trend of a decrease in personal conversations and the intimacy of conversations. Although ICT increased the frequency of communication and allowed for quicker and more direct (to-the-point) communication, the downside was that the need to interact and the intimacy of conversation decreased. Almost suggesting that as the quantity of communication increased, the quality of conversations decreased. It is interesting to note that one participant did not view this decrease as negative. She explained that younger generations are used to communicate with ICT, which has almost become the norm. She continued by pointing out: with ICT one is able at least to have a conversation with someone, even though one has to make use of ICT devices, whereas without ICT such a conversation might not have taken place.

\section{Discussion}

\section{Outline of the results}

The general objective of this study was to determine the impact ICT has on the work and personal lives of employees. The five themes extracted from the interviews provided valuable insights into the usage of ICT and the role these devices play in employees' environment. The findings did not only highlight employees' negative and positive experiences of ICT usage but also pointed out the role ICT plays in employees' relationships and the increased expectation brought about by adopting these devices. Although some of the findings are supported by previous research, the present research still contributed unique findings to literature on the role of ICT.

One unique finding from this research was the overall positive experiences of ICT outweighing the negative experiences. The participants experienced the role of ICT to be more positive than negative. Although previous research studies on this topic (Casey, 2012; Kakabadse et al., 2007; Zorn et al., 2008) highlight both positive and negative influences of ICT, they do not always indicate which type of experience take prevalence. The most mentioned positive experience of ICT, both at work and outside the work context, was the increased productivity and efficiency which
ICT devices provided employees which support the findings of Cardona, Kretschmer and Strobel (2013). Participants also mentioned that ICT increases their availability to their employer, clients, and their family members. This condition, however, results in employers and clients expecting employees to be more productive. Tarafdar et al. (2007) support this finding by stating that 'the use of ICTs comes with expectations for greater productivity' (p. 308).

The various options for communication with others also save time. Some participants explained that because they are able to communicate and share information with others through ICT, it eliminates travel time. Apart from saving time, ICT also saves costs for employees. This was particularly relevant for employees when using ICT outside their work domain. Participants mentioned that ICT provides cheaper alternatives to communicate through applications such as WhatsApp, which is less costly than a traditional text message. Besides providing a cheaper option for communication, ICT also allows employees to stay in touch with family members across geographical boundaries. Employees mentioned that they are able to communicate with distant family members, and still be part of their lives, through applications such as Skype. Ljung and Wahlforss (2006) mention that Skype does not limit individuals to telephone-like conversations but enables interaction in a more face-to-face manner. This could be seen as a contributing factor to employees who still experience themselves as part of distant family members' lives.

Regarding the negative role of ICT, the most dominant experience was the increased pressure brought about by these devices. One unique finding of the present research is the negative experience of ICT compromising the chain of command in organisations. Employees, particularly those in managerial positions, mentioned that ICT makes it difficult for them to manage their subordinates and departments. They continued to explain that ICT allows employees within the organisation to allocate tasks more easily to their subordinates without their knowledge.

ICT also creates distraction in employees' lives, specifically within their family domain, and takes time away from being with their families. Casey (2012) supports this observation by mentioning that ICT distracts individuals as they are partially attentive to the 'ping or beep' of their devices indicating yet 
another notification. As one participant to the present research mentioned, it is human nature to want to check these notifications. This also causes employees to lose track of time while they 'occupy' their ICT devices. Employees would initially just want to check the notification but would end up answering multiple mails, a task that could take up to an hour. Previous literature also found evidence of individuals who lose track of time while using their computers (Ainley, Enger \& Searle, 2008; Seymour, 2005).

A very interesting sub-theme, related to the negative experiences of ICT, was the total dependency on ICT. Employees mentioned a total dependency on ICT, especially for work, to such an extent where they became addicted to their ICT devices. This supports research on the notion that ICT addictiveness should be classified as a mental disorder in the Diagnostic and Statistical Manual of Mental Disorders (DSM). In many instances, this dependency is to such a degree that employees rely heavily on ICT devices to complete simple day-to-day activities and work assignments. Some employees indicated that they rarely leave their homes without their devices. This is particularly relevant for their mobile phones. The degree to which individuals become addicted to their phones is clearly illustrated by Walsh et al. (2008, p. 22) who report that individuals 'were so attached to their phone that they felt the mobile phone was a part of them'.

The availability and access provided by ICT devices also changed the norm of accessibility. Individuals are nowadays expected to be available throughout to both their employer and family, seeing that ICT allows them this scope of accessibility. Not only did the norm of accessibility change, but ICT also created renewed expectations of employees to be more productive. Employees mentioned that although a positive experience of ICT is increased efficiency, the adoption of ITC overstretches expectations of increasing productivity. One employee mentioned that, after the adoption of ITC, they are expected to complete tasks quickly with the 'push of a button'. Along with the expectation to be available throughout, they are also required to respond to messages in a shorter timespan than in the past. This could also contribute to the increased work pressure that employees' experience. The syndrome of such overstretched expectations of increased productivity and continuous accessibility is known as technostress (Tarafdar et al., 2007). Brod (1984), a well-known researcher in the field of technostress, defines this phenomenon as 'a modern disease of adaptation caused by an inability to cope with the new computer technologies in a healthy manner'.

ICT also played a significant role in the relationships within employee's work and family domains, both in a positive and negative way. Findings suggest that although ICT increases the frequency of communication between individuals, it decreased the quality of conversations. ICT helps employees to establish and maintain new relationships, particularly across geographical boundaries. Employees also mentioned that ICT helped them to build more productive relationships. By using ICT, employees found that they were more efficient in their communication and were able to provide information to their co-workers quicker and easier. Although previous literature indicates an increase in work productivity by using ICT (Kamaruzzaman et al., 2010; Kimathi, 2012; Mortagy et al., 2005), it does not mention the possibility of creating more productive relationships. Employees mentioned that ICT allowed them to communicate easily and quickly with others, saving them time. They continued to point out that by communicating with ICT they were able to 'get to the point' in conversations and avoid the personal aspect of the conversation, creating more productive relationships.

\section{Practical implications}

It is evident that an organisation should be aware of the impact of ICT on their employees and should strive to implement policies and procedures to assist their employees in managing the impact of ICT. As the present research highlighted the issue of increased expectations brought about by ICT, organisations should be aware of the expectancy from managers to reach their subordinates outside normal working hours which can become problematic. Employees may view such contact as infringement on their privacy as it provides managers with power outside the work environment. Managers should be realistic in their expectations of their employees. The downside is that organisations could face possible legal action based on their workers' ICT addiction brought about by the increased expectations to be available throughout (Kakabadse et al., 2007).

\section{Limitations and recommendations}

The present research is, however, not without certain limitations. Using interviews meant the researchers relied on self-reported data as source of information. Although self-report data is a research method commonly used in behavioural research, researchers should be aware of its limitations (i.e. social desirability, recall bias, and mental editing). In addition, this research only investigated the employees themselves and did not extend the unit of analysis to include the households of the employees (esp. the partner or spouse). Additional information could have been gathered, especially concerning the type of ICT devices the participants utilised.

Future research could specifically investigate the relationship between the degree of ICT adoption - both by the employee and the organisation. A possible suggestion would be a comparative study between organisations with high degree of ICT use and those whose employees show less ICT use. A comparative research can also be done on the differences between employees using one device against those using multiple devices. The focus can be on differences in (1) their WLI, (2) the decrease in face-to-face communication, and (3) their dependency on ICT. The trend the current research identified according to which ICT increases the frequency of communication but decreases the quality of conversations could also be investigated in more detail. This could be done 
by focusing research particularly on the influence ICT usage exerts on communication between employees and their coworkers, as well as with family members. Organisations can implement a code of conduct or provide guidelines to try and eliminate intrusive and excessive use of ICT, specifically after working hours. This strategy is supported by previous literature which mentions that by implementing limits on contacting employees outside working hours the inappropriate use of ICT can be decreased (Drew \& Murtagh, 2005). Also, organisations should consider implementing a hierarchical policy with regard to ICT (to ensure the correct communication channels are followed for instructions and tasks regarding employees). As mentioned by the participants, particularly the managers, ICT compromised the hierarchy of an organisation and made it difficult to manage their subordinates.

\section{Conclusion}

The research showed valuable insights into the role of ICT on employees' work and family domains. It was evident from the data that the role of ICT was predominantly experienced as positive, although some negative influences were also experienced. Participants also indicated a degree of dependency on ICT to complete everyday work and family tasks. The role of ICT on employees' relationships was also experienced as positive and negative. The research highlighted that employees should make a conscious decision in managing their ICT to decrease the negative influence thereof on their domains.

\section{Acknowledgements Competing interests}

The authors declare that they have no financial or personal relationships which may have inappropriately influenced them in writing this article.

\section{Authors' contributions}

W.d.W. was in charge of the study design, data collection, data analysis and the write-up of the total manuscript. E.K. was the supervisor of the study who assisted in the data analysis and write-up of the manuscript. J.A.N. evaluated the total manuscript and prepared it for publication.

\section{References}

Achimugu, P., Oluwagbemi, O., \& Oluwaranti, A. (2010). An evaluation of the impact of ICT diffusion in Nigeria's higher educational institutions. Journal of Information Technology Impact, 10(1), 25-34.

Afolabi, A.F., \& Abidoye, J.A. (2011). Integration of information and communication technology in library operations towards effective library services. Journal of Educational and Social Research, 1, 113-120.

Ainley, J., Enger, L., \& Searle, D. (2008). Students in a digital age: Implications of ICT for teaching and learning. In J. Voogt \& Knezek, G. (Eds.), International handbook of information technology in primary and secondary education (pp. 63-80). Boston MA: Springer US.

Arvanitis, S., \& Loukis, E. (2014). An empirical investigation of the impact of ict on innovation in european hospitals. Presented at the 22nd European Conference on Information Systems, Tel Aviv, Israel.

Barbour, R.S. (2001). Checklists for improving rigour in qualitative research: A case of the tail wagging the dog? British Medical Journal, 322(7294), 1115-1117.

Berkowsky, R.W. (2013). When you just cannot get away. Information, Communication \& Society, 16(4), 519-541. http://dx.doi.org/10.1080/1369118X.2013.772650
Bogdan, R., \& Biklen, S. (1998). Qualitative research in education. An introduction to theory and methods. Retrieved October 12, 2014, from http://eric.ed. $\mathrm{gov} /$ ?id=ED419813

Braun, V., \& Clarke, V. (2006). Using thematic analysis in psychology. Qualitative Research in Psychology, 3(2), 77-101. http://dx.doi.org/10.1191/1478088706qp063oa

Brod, C. (1984). Technostress: the human cost of the computer revolution. Boston, MA: Addison-Wesley.

Cardona, M., Kretschmer, T., \& Strobel, T. (2013). ICT and productivity: Conclusions from the empirical literature. Information Economics and Policy, 25(3), 109-125. http://dx.doi.org/10.1016/j.infoecopol.2012.12.002

Carrol, J., Howard, S., Vetere, F., Peck, J. \& Murphy, J. (2002). Just what do the youth of today want? Technology appropriation by young people: Proceedings of the 35 th Hawaii International Conference on System Sciences. Honolulu, HI.

Casey, J. (2012). The impact of technology on our work and family lives. Retrieved November 2, 2014, from http://goo.gl/k8g3QS

Chesley, N., \& Johnson, B. (2010). Information and communication technology, work, and family. In S. Seet, \& J. Chesley (Eds.), Work and family encyclopaedia. Boston, MA: Sloan Work and Family Research Network Chestnut Hill. Retreived MA: Sloan Work and Family Research Network Chestnut Hill. Retreived ej08hr00at6ew6q3

Delmas, N. (2014). ITU Key 2005-2014 ICT Data. International Communications Union. Retrieved November 02, 2014, from http://www.itu.int/en/ITU-D/Statistics/ Pages/stat/default.aspx

De Vos, A., Delport, C., Fouché, C., \& Strydom, H. (2011). Research at grass roots: A primer for the social science and human professions. Pretoria, South Africa: Van Schaik.

Drew, E., \& Murtagh, E.M. (2005). Work/life balance: Senior management champions or laggards? Women in Management Review, 20(4), 262-278. http://dx.doi.org/ 10.1108/09649420510599089

Du Plessis, E. \& Human, S. (2007). Exploring a stategy to promote nurses' health research contribution. Health SA Gesondheid, 12(4), 36-52. http://dx.doi.org/ 10.4102/hsag.v12i4.271

Fallahi, V. (2011). Effects of ICT on the youth: A study about the relationship between internet usage and social isolation among Iranian students. Procedia: Social and BehavioralSciences, 15, 394-398. http://dx.doi.org/10.1016/j.sbspro.2011.03.110

Hall, B.H., Lotti, F., \& Mairesse, J. (2013). Evidence on the impact of R\&D and ICT investments on innovation and productivity in Italian firms. Economics of Innovation and New Technology, 22(3), 300-328. http://dx.doi.org/10.1080/1043 8599.2012.708134

Higon, D.A. (2011). The impact of ICT on innovation activities: Evidence for UK SMEs. International Small Business Journal, 30(6), 684-699. http://dx.doi. org/10.1177/0266242610374484

Hill, C.E., Knox, S., Thompson, B.J., Williams, E.N., Hess, S.A., \& Ladany, N. (2005) Consensual qualitative research: An update. Journal of Counseling Psychology, 52(2), 196-205. http://dx.doi.org/10.1037/0022-0167.52.2.196

Kakabadse, N., Porter, G., \& Vance, D. (2007). Addicted to technology. Business Strategy Review, 18(4), 80-85.

Kamaruzzaman, S., Salled, H., Zawawi, E., \& Ali, A. (2010). Current use and needs of ICT in Malaysian building industry: The industry perspective. Design and Built Journal, 3, 74-84.

Kılıçaslan, Y., Kayıș, A.A., Sickles, R., \& Üçdoğruk, Y. (2013, October 24-25). The Impact of ICT on productivity: Evidence from Turkish manufacturing industry.
EY International Congress on Economics I (EYC2013), Ankara, Turkey, 24-25 EY International
October 2013.

Kimathi, K. (2012). Impact of ICT in education entertainment, development governance/politics \& industry. Retrieved December 02, 2014, from http://goo.gl/ governanc
gT4iab

Koutamanis, M., Vossen, H.G.M. Peter, J \& Valkenburg, P.M (2013). Practice makes perfect: The longitudinal effect of adolescents' instant messaging on their ability to initiate offline friendships. Computers in Human Behavior, 29(6), 2265-2272 to initiate offline friendships. Computers in H
http://dx.doi.org/10.1016/j.chb.2013.04.033

Kumar, R., \& Prasad, Y. (2014). Impact of ICT tools in Higher Education. Delhi, India: A K Publications.

Lasrado, F., \& Bagchi, T. (2011). A cross-cultural evaluation of the contemporary workplace and its managerial implications. Social Sciences, 2(1), 1-15.

Leask, M., \& Pachler, N. (2013). Learning to Teach Using ICT in the Secondary School: A companion to school experience (3rd ed.) New York, NY: Routledge.

Lindquist, E. (2013). What's your name on Facebook. Retrieved October 19, 2014, from http://lup.lub.lu.se/student-papers/record/3798810/file/3798813.pdf

Lindsay, S., Smith, S., \& Bellaby, P. (2007). The impact of ICT on family: Views from an older generation. Retrieved October 07, 2014, from http://goo.gl/rOESHi

Livingstone, S. (2012). Critical reflections on the benefits of ICT in education. Oxford Review of Education, 38(1), 9-24. http://dx.doi.org/10.1080/03054985.2011.577938

Ljung, A., \& Wahlforss, E. (2006). Sensation : A presence enabler for long-distance relationships using Skype and Visual Presence Representation. Retrieved November 22, 2014, from http://goo.gl/U3WvBU

Madden, M., \& Jones, S. (2008). Networked workers. Technical report. Pew Internet and American Life Project.

Maree, K. (2008). First steps in research. Pretoria, South Africa: Van Schaik.

Marius, M. (2012). 6 ways technology is changing the way we do business. Retrieved November 2, 2014, from http://goo.gl/Uc08qR 
Mays, N. (2000). Qualitative research in health care: Assessing quality in qualitative research. British Medical Journal, 320(7226), 50-52. http://dx.doi.org/10.1136/ bmj.320.7226.50

Mortagy, Y., Boghikian-Whitby, S., \& Mortagy, B. (2005). The utilization of ICT in small and medium size enterprises in Egypt. Retrieved October 01, 2014, from http://goo.gl/v85fcx

Ollo-López, A., \& Aramendía-Muneta, M.E. (2012). ICT impact on competitiveness, innovation and environment. Telematics and Informatics, 29(2), 204-210. $\mathrm{http}: / / \mathrm{dx}$.doi.org/10.1016/j.tele.2011.08.002

Papadakis, M., \& Collins, E. (2001). The application and implications of information technologies in the home: Where are the data and what do they say? Arlington, VA: National Science Foundation.

Piazza, C.F. (2007, January 23). 24/7 workplace connectivity : A hidden ethical dilemma. Paper presented at Business and Organizational Ethics Partnership, Markkula Center for Applied Ethics, Santa Clara University, Santa Clara, CA. Retrieved September 21, 2014, from
focusareas/business/connectivity.pdf

Polkinghorne, D.E. (2005). Language and meaning: Data collection in qualitative research Journal of Counseling Psychology, 52(2), 137-145. http://dx.doi.org/10.1037/00220167.52.2.137

Preda, A., Crisan, D., \& Stanica, J. (2014). The impact of ICT on innovation performance in Europe: Case of Romania. Journal of Information Systems \& Operations Management, 8(1), 197-206.

Raworth, K., Sweetman, C., Narayan, S., Rowlands, J., \& Hopkins, A. (2012). Conducting semi-structured Interviews. Oxford, UK: Oxfam.

Rincon, A., Vecchi, M., \& Venturini, F. (2012). ICT spillovers, absorptive capacity and productivity performance. Retrieved October 07, 2014, from http://eprints.mdx. productivity perf

Salehan, M., \& Negahban, A. (2013). Social networking on smartphones: When mobile phones become addictive. Computers in Human Behavior, 29(6), 2632-2639. http://dx.doi.org/10.1016/j.chb.2013.07.003

Saltari, E., Wymer, C.R., \& Federici, D. (2013). The impact of ICT and business services on the Italian economy. Structural Change and Economic Dynamics, 25, 110-118. $\mathrm{http}: / / \mathrm{dx}$.doi.org/10.1016/j.strueco.2012.07.004

Schmidt, A., Pfleging, B., Alt, F., Sahami, A., \& Fitzpatrick, G. (2012). Interacting with 21st-century computers. IEEE Pervasive Computing, 11(1), 22-31. http://dx.doi. org/10.1109/MPRV.2011.81
Seymour, W. (2005). ICTs and disability: Exploring the human dimensions of technological engagement. Technology and Disability, 17(4), 195-204.

Shenton, A. (2004). Strategies for ensuring trustworthiness in qualitative research projects. Education for Information, 22, 63-75.

Shirazi, F., Ngwenyama, O., \& Morawczynski, O. (2010). ICT expansion and the digital divide in democratic freedoms: An analysis of the impact of ICT expansion, education and ICT filtering on democracy. Telematics and Informatics, 27(1), 21-31. http://dx.doi.org/10.1016/j.tele.2009.05.001

Snape, D., \& Spencer, L. (2003). The foundation of qualitative research. In J. Ritchie \& J. Lewis (Eds.), Qualitative research practice: A guide for social science students and researchers (pp. 1-23). London, UK: Sage publications.

Stahl, B., Heersmink, R., Goujon, P., \& Flick, C. (2010). Issues, concepts and methods relating to the identification of the ethics of emerging ICTs. Communications of the IIMA, 10(1), 33-43.

Tarafdar, M. Tu, Q Ragu-Nathan, B, \& Ragu-Nathan, T (2007). The impact of Technostress on role stress and productivity. Journal of Management Information Systems, 24(1), 301-328. http://dx.doi.org/10.2753/MIS0742-1222240109

Tolani-Brown, N. (2010). ICTS and sustainable solutions for the digital divide. New York: IGI Global.

Tusubira, F., \& Mulira, N. (2004, September). Integration of ICT in organizations: Challenges and best practice recommendations based on the experience of Makerere University and other organizations. Paper presented at Universities, Kampala: Taking a leading role in ICT enabled human development.

Van der Knaap, W. (2014). The impact of ICT on spatial planning education: 25 years of blended e-learning. In L. Chova, A. Martinez, \& I. Torres (Eds.), 6th International Conference on Education and New Learning Technologies (pp. 6136-6147). Barcelona, Spain: IATED.

Wagner, C., Kawulich, B., \& Garner, M. (2012). Doing social research: A global context Bershire, UK: McGraw-Hill Higher Education.

Walsh, S., White, K., \& Young, R. (2008). Over-connected? A qualitative exploration of the relationship between Australian youth and their mobile phones. Journal of Adolescence, 31(1), 77-92.

Zorn, T., Hector, C., \& Gibson, J. (2008, May 22-26). Perceived effects of information and communication technology adoption on quality of work life: An exploratory study. Presented at The 58th Annual Meeting of the International Communications Association, Montreal, QC. 